\title{
A CASE OF LIPOIDOSIS FOLLOWING Rh FACTOR INCOMPATIBILITY
}

\author{
BY \\ L. CROME \\ From the Fountain Hospital, Tooting, London
}

(RECEIVED FOR PUBLICATION SEPTEMBER 10, 1955)

The present knowledge of the morphological changes in cases of residual kernicterus is based on the descriptions of 17 cases, to which I was able to add another two (Crome, 1955). The changes were characterized by focal lesions in the globus pallidus, corpus Luysii, and diffuse loss of nerve cells in the cerebral cortex. The two cases mentioned above were in a series of 140 consecutive necropsies of low-grade mental defectives at the Fountain Hospital. A third case of the same series with established factor incompatibility, neonatal jaundice, and erythroblastosis foetalis presented, however, a different clinical picture, and the morphological changes at necropsy were those of a lipoidosis. It seemed useful, therefore, to record this case.

\section{Case Report}

The patient's mother had three normal children by two different men before she entered upon an incestuous relationship with her brother, the issue of which was another normal child followed by a miscarriage and then by the patient. The patient's father had had malaria and was reported to be very nervous and a heavy drinker. His blood group is not known.

The mother, who is of normal intelligence, was assaulted and beaten during the patient's gestation and had unspecified kidney trouble. She is rhesus negative, cde/cde, and had had a transfusion of rhesus-positive blood a year before her confinement. Her blood serum contained rhesus antibodies of anti-D type, and she was warned that the child would be jaundiced. She was 40 years old at the time of the confinement.

Labour was induced by injection at eight months, and the child, a male weighing $7 \mathrm{lb}$., was delivered by forceps. Deep jaundice developed within a few hours, the Coombs test was positive, the blood group was $R_{2} r, O$, and the infant's haemoglobin (Haldane $100 \%=148 \mathrm{~g} . \%$ ) fell to $70 \%$. He was transfused with $70 \mathrm{ml}$. of rhesus negative blood. At 12 days the haemoglobin was $92 \%$ and the jaundice had cleared.

He was taken later to an out-patient department of another hospital at the age of 3 weeks. At that time he was pale, haemoglobin being $80 \%$, gradually dropping to $68 \%$ at 6 weeks, when he was admitted to hospital for possible transfusions. His weight was at that time $9 \mathrm{lb}$., and there was slight splenomegaly and hepatomegaly. Blood transfusion was not repeated, however, and when last seen at that hospital aged $2 \frac{1}{2}$ months the haemoglobin was $84 \%$ with $5,000,000$ R.B.C.s. He was regarded as a case of haemolytic disease of the newborn.

The retardation of the patient's mental and physical development was noticed early. His mother considered that he was deaf and blind, and thinks that he may have had epileptic fits.

He was admitted to the Fountain Hospital at 1 year and 5 months. His mental state was that of an idiot. He could crawl about aimlessly in his cot, did not react to speech, but it is possible that he heard loud noises. He did not grasp objects placed in his hand. Spasms, twitching, and irregular movements were noticed at various times during his stay in hospital, their nature remaining uncertain. Some observers regarded them as epileptic attacks, others as choreiform movements. There was likewise no unanimity regarding the diagnosis. Some considered him to be a case of residual kernicterus, others inclined to the view that the condition was one of arrested development associated with a diffuse cortical agenesia and persistence of infantile movements. This second opinion was supported by an E.E.G. recorded at 2 years and 5 months. There was no significant rhythmic activity seen at any frequency even with the gains turned up, and no variation with eye opening and closure.

His vision was doubtful. The left pupil reacted to light, the right did not. The optic discs were normal. The retinae were abnormally thin, the choroid showing through clearly. The muscles in all parts of the body were hypotonic. The tendon jerks were present and not exaggerated, but the plantar responses were extensor.

The urine test for phenylketonuria, the blood Wassermann, and Meinicke and the Mantoux reaction were all negative. The C.S.F. was normal.

During the last few months of his life the patient suffered from recurrent attacks of respiratory infection and pyrexia without obvious cause. He con- 
tracted measles at the age of 2 years and 7 months. This was followed by bronchopneumonia, from which he died.

Five years after the patient's birth his mother had another child by her first husband. The pregnancy was uneventful, but at three weeks' gestation she showed rhesus antibodies in the serum to the titre of 1 in 32, rising to 1 in 128 just before delivery. The baby had a good colour at birth with the $\mathrm{Hb} 105 \%$, but the direct Coombs test was positive and an exchange transfusion was performed successfully. The haemoglobin did not fall, and no further transfusion was necessary.

As far as could be judged this baby developed normally, with no sign of kernicterus, up to the age of 6 months when he was last seen. The father's blood group was not ascertained.

\section{Pathological Findings}

The subject at necropsy, performed 12 hours after death, was emaciated, weighing $9.1 \mathrm{~kg}$. with height $88.8 \mathrm{~cm}$.; the head measured $45 \mathrm{~cm}$. in circumference, and was symmetrical and free from deformity. The trachea and bronchi contained mucopurulent secretion. A " geographical" pattern of coalescent areas of lobular collapse and consolidation was present on the surface of the lungs. The liver and spleen were large, weighing 554 g. (normal 400 g.*) and 50 g. (normal 35 g.) respectively. A considerable amount of fatty change was seen in the liver. The spleen was firm, of normal size, and the Malpighian bodies were small. Enlarged lymph nodes were palpable in the mesentery. The testes, situated in the inguinal canals, were small.

The microscopical examination of the lungs confirmed the presence of partial and complete lobular collapse. Bronchioles were infected and their lumina occluded, and inflammatory infiltration had spread to surrounding alveoli in some areas while others showed vasodilatation and infiltration with phagocytic cells, some of which were large and multinucleated. Staining of frozen sections with scarlet $\mathbf{R}$ revealed numerous sudanophil inclusions in these cells, almost all of which could be dissolved and eliminated by treatment with a simple fat solvent, such as ether or chloroform.

The liver showed considerable fatty change affecting parenchymatous cells but without any particular zonal or focal distribution. After the elimination of the fatty material with fat solvents it was possible to identify other faintly sudanophil granules in the Kupffer cells which were not birefringent. The Kupffer cells were enlarged, measuring about $30 \mu$, and most of them were

\footnotetext{
* Normal weights of all organs are taken from Copoletta, J. M., and Wolbach, S. B. (1933). Amer. J. Path., 9, 55.
}

oval or irregular in shape. Thin round nuclei were mostly at the periphery of the cells, staining darkly and homogeneously with haematoxylin. The granular sudanophil material in them was not soluble in ether, chloroform, xylol, petrol ether, benzol, alcohol, carbon tetrachloride, or amyl acetate.

There was no detectable increase in the amount of collagen or reticulin in the portal tracts of the liver.

The spleen and lymph nodes also contained some cells similar in shape and staining property to the abnormal Kupffer cells. They could be seen in the sinusoids and Malpighian corpuscles of the spleen and in the sinuses of the lymph nodes, being easily recognizable in the haematoxylinstained paraffin sections by their size, the smallness of the nuclei, and the finely granular basophilic cytoplasm (Fig. 1). These adventitious cells were most numerous in the lymph nodes, less so in the spleen, and least in the liver.

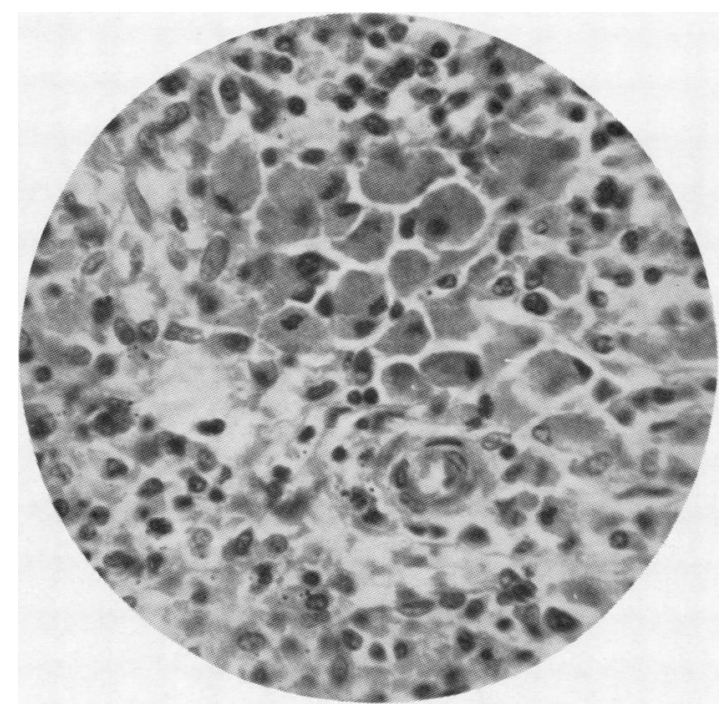

FIG. 1.-Adventitious cells in a sinus of a lymph node. Haematoxylin and eosin $\times 4$.

Central Nervous System.- There was a large amount of clear fluid in the subdural space. The brain was small, the formalinized cerebrum weighing $312 \mathrm{~g}$. and the cerebellum with the brain-stem $116 \mathrm{~g}$. (total normal weight $1,100 \mathrm{~g}$.). The soft meninges were thickened and opaque over the cerebrum and clear over the cerebellum. All the cerebral veins were intensely congested, some of them containing recent ante-mortem thrombi. There was a large area of meningeal haemorrhage measuring $2 \frac{1}{2}$ by $1 \frac{1}{2} \mathrm{~cm}$. on the medial surface of 
the left frontal lobe. The cranial nerves and arteries were normal.

The cerebrum was firm, almost cartilage-like in consistency, and showed marked wasting of the gyri with a corresponding widening of the sulci. This was particularly evident in the frontal lobes (Figs. 2 and 3). The gyri were normal in number and position. Some opercular defect was present on both sides, and the corpus callosum was uniformly thin and the foramina of Munro dilated.

A marked but variable reduction in the thickness of the cortex was seen in coronal sections of the cerebral hemispheres. A thin line of rarefaction, parallel to the surface and situated at about the middle of the cortex, was visible in many areas. The white matter was ivory white and very firm. The basal ganglia appeared to be normal with the exception of the dorso-medial nucleus of the thalamus which was paler than usual. The whole of the ventricular system was uniformly dilated.

The cerebellum was relatively large and changes in it were less obvious. Close naked-eye inspection of its cut surface revealed, however, lessened contrast in the pattern of the arbor vitae, the

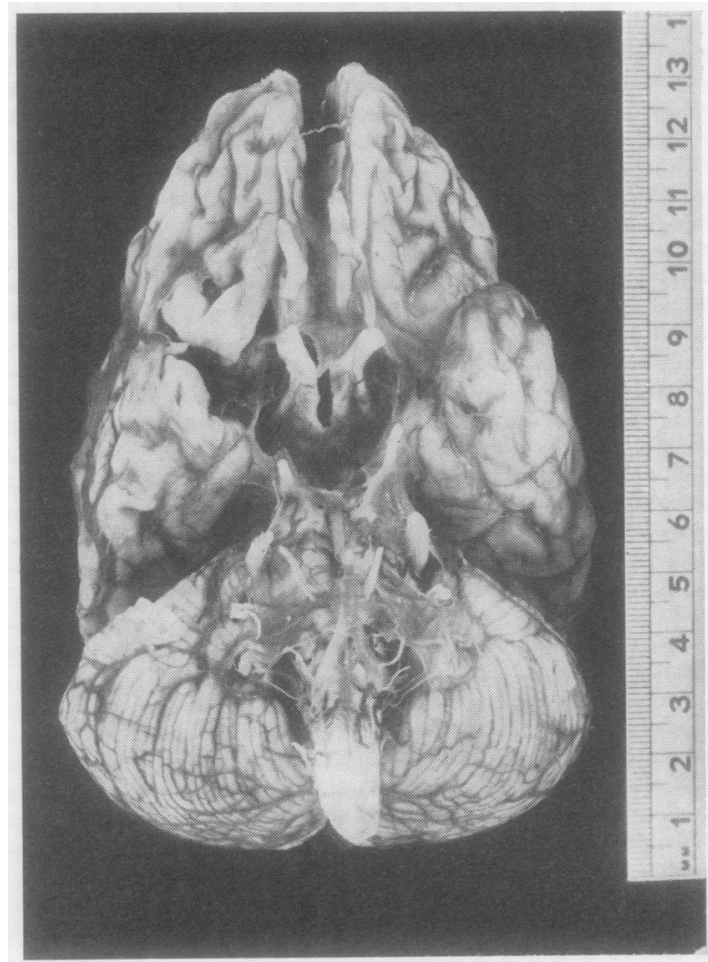

FIG. 2.-Basal view of the brain, showing marked atrophy, especially of the frontallobes.

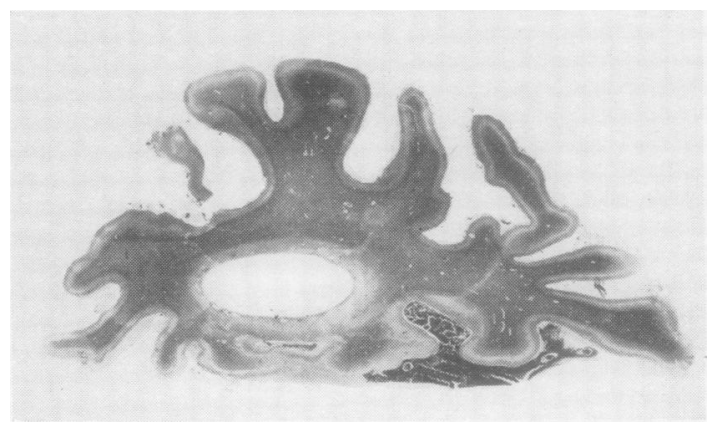

FIG. 3.-Coronal section of occipital lobe, showing shrinking of the gyri and dilatation of the sulci. Holzer, natural size.

change being more obvious in some of the folia. The cerebellar consistency was somewhat increased.

No naked-eye abnormality could be seen in the brain-stem or spinal cord.

\section{Microscopical Examination}

Representative sections of the brain and spinal cord were embedded in celloidin and paraffin and treated with the customary neurohistological stains. Frozen sections were used for silver impregnation and staining of lipoid material. Solubility of the adventitious intracellular material was assessed by treatment with fat solvents already enumerated, and sections were also stained with scarlet $R$, Sudan black, osmic acid, Nile blue sulphate, Weigert's haematoxylin, P.A.S. reagent, and by the Smith-Dietrich method.

All cells throughout the central nervous system, with some exceptions to be specified below, were affected by lipoidosis. They showed varying degrees of distension or irregular ballooning of the cell bodies and dendrites (Fig. 4). The substance contained in the cytoplasm was seen to be faintly granular in the Nissl sections of the better preserved cells. No granules could be recognized in the very numerous degenerating cells, the cytoplasm of which stained only faintly or not at all. The nucleus was displaced to one side of the cell, into one of the dentrites or the axon hillock. It was frequently hyperchromatic but usually stained more faintly in the degenerating cells; it could not be identified at all in the "ghost forms." The nucleolus stained well in most of the cells. The neurofibrillary apparatus was defective, the few persisting fibrils being condensed around the periphery of the cell.

The adventitious substance in the nerve cells was identical with that described in the cells of the reticulo-endothelial system. It stained faintly 


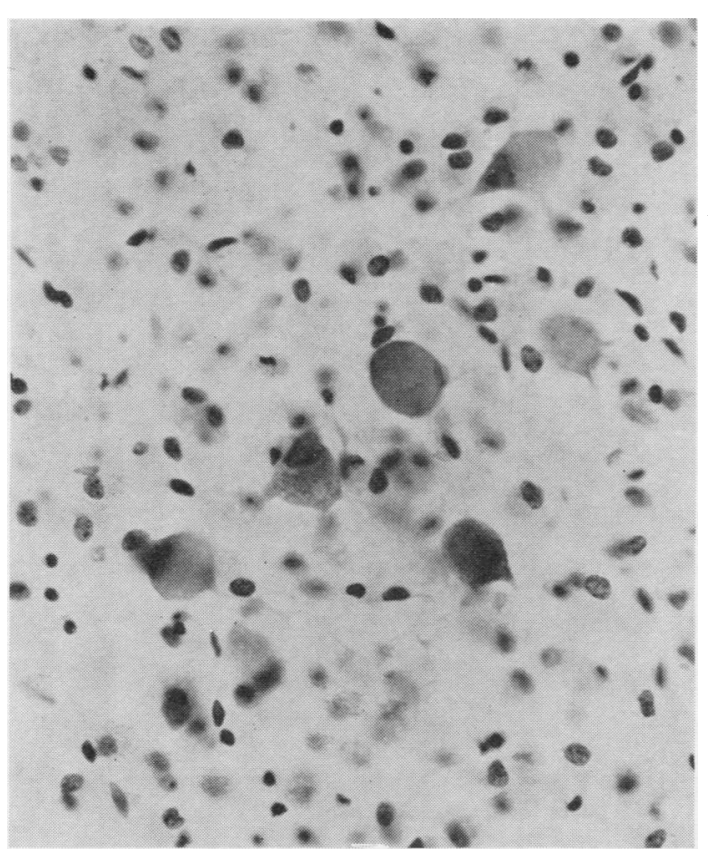

Fig. 4.-Cerebral cortex showing some nerve cells distended by lipoid and numerous glial cells. Cresyl violet $\times \mathbf{4 0 0}$.

orange to red with scarlet $\mathbf{R}$ presenting both as minute granules and diffuse homogeneous material. It was argentophil and stained blue with Nile blue sulphate, black with Sudan black, and was positive to periodic acid. It did not stain with the original or the Smith-Dietrich modification of the Weigert stain. It resisted all fat solvents.

The neuronal lipoidosis was most marked in the following areas: the cerebral cortex, hypothalamus, nuclei pontis, habenular nuclei, the large cells of the striate body, the large cells of the red nucleus, the cerebellar Purkinje cells, the dentate nuclei, and anterior horns of the spinal cord. It was less conspicuous in the small cells of the striate body, the pyramidal cells of the hippocampus, the substantia nigra and locus caeruleus, the small cells of the red nuclei, in many individual and groups of cells in the reticular formation of the brain-stem, in the multipolar cells of the cranial nerve nuclei, in the inferior olives, and in the posterior horns of the spinal cord. The granular cells of the hippocampus and nerve cells in the granular layer of the cerebellum were not visibly affected.

Considerable other structural changes were also present in the cerebral cortex. It was reduced in width and status spongiosus accounted for the cleft visible over much of the cortex on naked-eye inspection. All traces of normal lamination were obliterated, the spongy cleft corresponding approximately to the normal position of lamina III, IV, or V. Almost all nerve cells were absent in the superficial layers, and the remaining few in the deeper ones were degenerate. Glial cells were increased in number, consisting of protoplasmic and fibrous astrocytes with microglial compound granular corpuscles containing the same adventitious material as the nerve cells. There was also a marked proliferation of capillaries formed by somewhat swollen endothelial cells. No increase in collagen fibres could be detected in the cortex, but an early stage of reticulum fibre formation was seen around the lumina of many capillaries in sections stained by the Perdrau method. Compound granular corpuscles containing bright red sudanophil material soluble in fat solvents, together with a number of anisotropic granules, were also seen in some of the cortical Virchow-Robin spaces. Fibrous gliosis extended throughout the whole thickness of the cortex. The changes described above were present throughout the cortex, being somewhat milder in the insula and temporal lobes. The only change in the hippocampus was a slight loss of cells in the Sommer sector.

The leptomeninges were thickened and contained some lymphocytes and macrophages in intertrabecular meshes of loose connective tissue.

Profound changes were also seen in the cerebral white matter. The myelin was pale in sections stained by the Heidenhain and Kulschitsky$\mathrm{Pal}$ methods, higher magnification revealing myelin sheaths in all stages of disintegration. Fibrous gliosis was widespread, being densest in areas corresponding to the greatest loss of myelin, and glial cells were increased in number. Some of these were compound granular corpuscles, others hypertrophied protoplasmic astrocytes. A large amount of soluble sudanophil material lay freely and in compound granular corpuscles. More anisotropic material was found than in the cortex.

The internal capsule was reduced in width and its myelin was pale. The dorso-medial nucleus of the thalamus also showed considerable pallor of myelin (Fig. 5) with a correspondingly dense fibrous gliosis, loss of nerve cells, and proliferation of micro- and macroglia. Mild fibrous gliosis was present in the superior and medial parts of the ventro-lateral thalamic nucleus. A similar change was seen in the subventricular superficial part of the body of the caudate nucleus. Other parts of the basal ganglia showed little change. There was some fibrous gliosis without detectable loss of myelin or nerve cells in the globus pallidus. No change, other than neuronal lipoidosis, was seen in the red nucleus or the substantia nigra. 


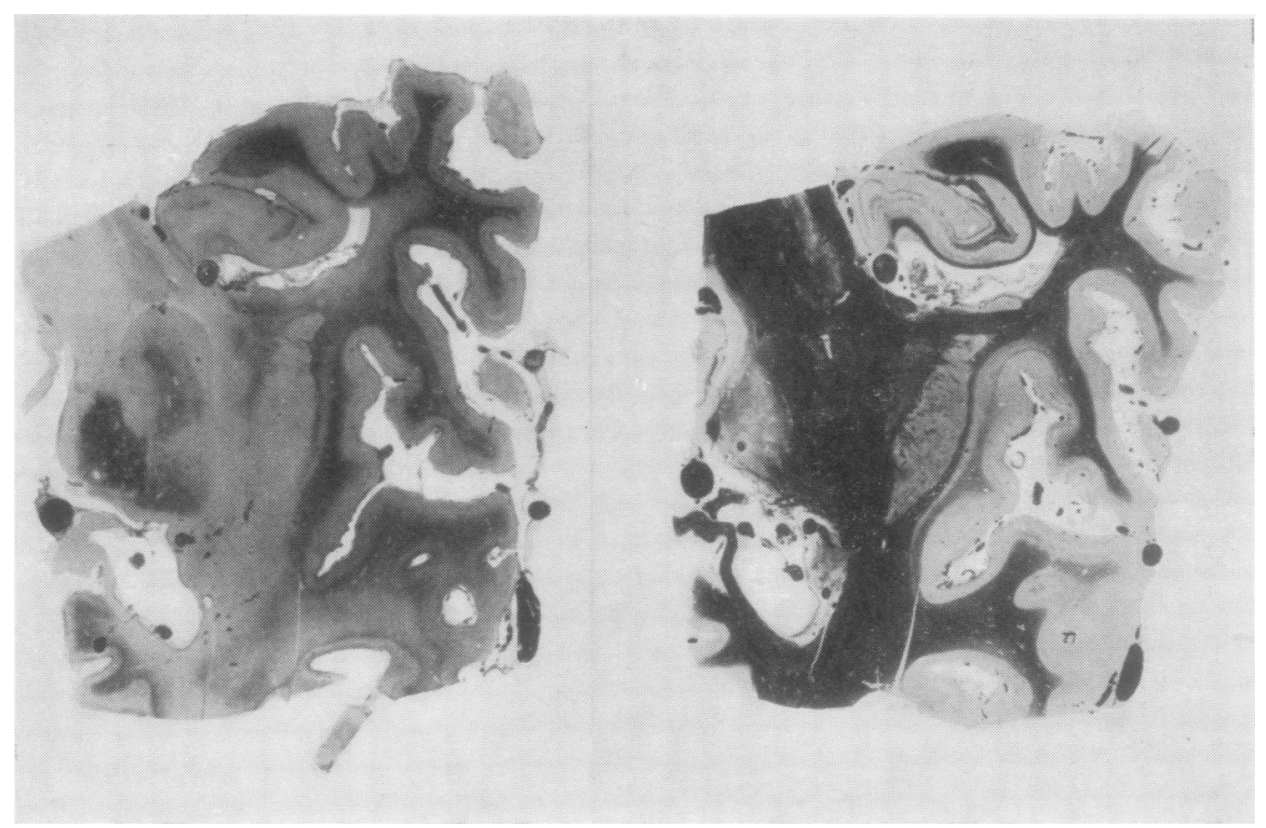

FIG. 5

The brain-stem showed no perceptible loss of nerve cells. There was, however, pronounced marginal and periventricular fibrous gliosis. Fibrous gliosis was also seen in the basal portions of the mid-brain and pons, in the inferior olives, and throughout the tegmentum. The pyramids were flattened and the myelin in them pale.

The granular layer of the cerebellum was atrophied (Fig. 6). It contained an excess of astrocytes and microglial cells filled with the adventitious sudanophil material. The granular cells, however, did not, as mentioned above, contain this material. Marked fibrous gliosis was also present.

The molecular layer was not appreciably reduced in size. It contained a very dense perpendicular layer of glial fibres. The Bergmann glia were increased in number. The Purkinje cells, although affected by the lipoidosis, were not greatly diminished in number. Their dendrites in the molecular layer were considerably distended and contained lipoid material. The pericellular baskets were present, some of them being, perhaps, reduced in number.

The myelin was pale in the lateral and the anterior columns in the Heidenhain sections of the cord. Fibrous gliosis was present in the spinal

FIG. 5.-Basal ganglia. Heidenhain stain, left, and Holzer stain, right, $\times 1 \frac{1}{2}$.

FIG. 6.-Cerebellum showing that the Purkinje cells are ballooned but most of them are present. The granular layer is atrophic. Cresyl violet $\times 60$.

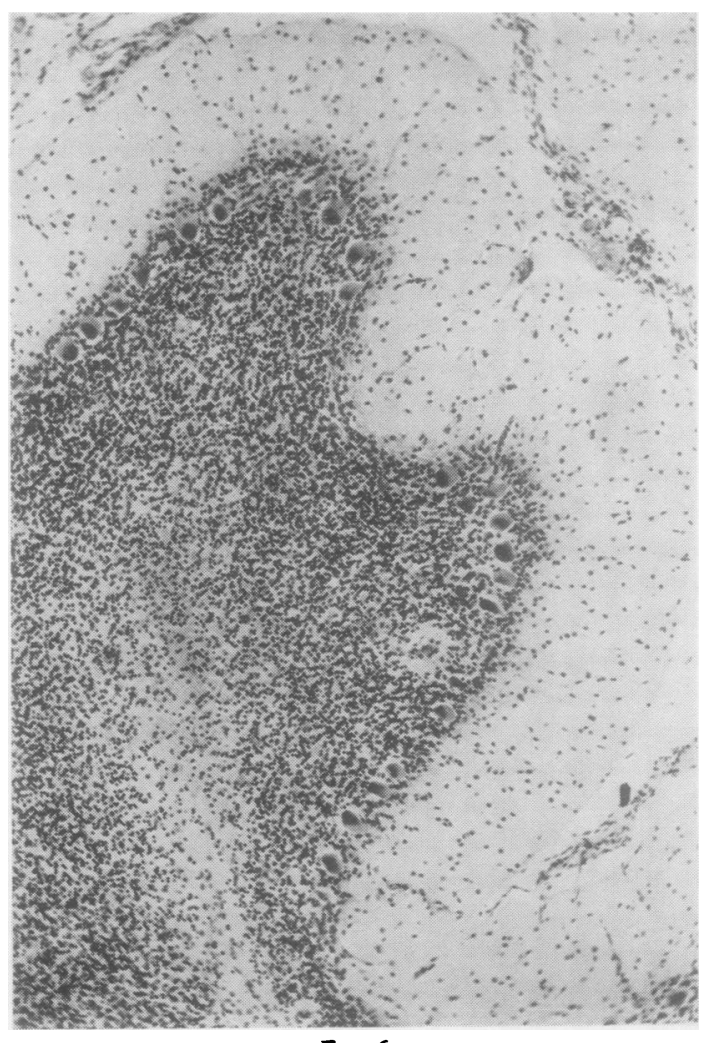

Fio. 6 
grey matter, being particularly marked around its periphery.

Most of the cells in the posterior pituitary appeared to be normal. Some distension of the cytoplasm by basophilic, faintly granular material could be observed in a few of them. No processes could be identified, however, in these cells and it remained uncertain whether they were of nervous or reticulo-endothelial origin.

The ganglion cell layer of the retina was depleted, containing few nerve cells all of which showed neuronal lipoidosis. Glial cells were increased in number in this layer. The external granular layer was thin in some areas and entirely absent in others.

\section{Biochemistry}

Formalinized cerebral material was examined by Mr. R. Rodnight. The cortex proved to be too thin for separate analysis. The total cholesterol of the white matter was $2.64 \%$ of the wet tissue (normal range : $3.8-4.3 \%$ ). Free cholesterol was $1.64 \%$ and ester cholesterol $1 \%$. Cerebrosides were $1.11 \%$ (normal range : $4.5-5.5 \%$ ).

The lipids in the spleen were estimated by Dr. L. I. Woolf. They totalled $4 \%$ of wet tissue (normal 2.3\%). Glucose released on hydrolysis was about $2.5 \mu \mathrm{g} . / 100 \mathrm{mg}$. of spleen. Galactose released was 2-3 $\mu \mathrm{g}$. $/ 100 \mathrm{mg}$. with a trace of galactosamine. The total lipid nitrogen was $0.074 \%$ of fresh spleen. About half of the nitrogen remained in the lipid fraction after hydrolysis.

\section{Discussion}

The serological evidence and clinical history leave little doubt as to the $\mathrm{Rh}$ factor incompatibility and erythroblastosis foetalis in this case. It presents, however, certain unusual features.

The clinical sequelae of $\mathrm{Rh}$ sensitization have been fully described by Pentschew (1948), Pickles (1949), and by Evans and Polani (1950). These workers mentioned the variability of the clinical manifestations in this condition, but suggested nevertheless that they followed a certain pattern. A stormy neonatal period with jaundice, drowsiness, feeding difficulties, opisthotonos, and respiratory disturbances is usually followed between the age of 1 and 2 years by a "silent" period. After that, rigidity, intermittent opisthotonos and involuntary movements make their appearance. Hypertonia may be present and this may be replaced by intermittent spasms resembling athetosis. Involuntary choreiform movements may set in later, and deafness is also common. Mental defect is present in some cases, while the intelligence is normal in others. In a further article Pentschew (1949) stressed again that mental activity remains remarkably little disturbed in many of these cases and that some neurological improvement can also be seen in the course of years. The manifestations of $R h$ sensitization in mental defectives have been studied by Crome, Kirman, and Marrs (1955). Their findings correspond, on the whole, with those of the earlier workers, a number of cases presenting a similar picture with athetosis, deafness and a relatively well preserved mental capacity, though in others the damage appears to be more extensive, even to the extent of complete idiocy.

Knowledge of the structural changes caused by $\mathrm{Rh}$ sensitization rests upon a large number of observations in patients dying in the neonatal period with icterus gravis reviewed by Becker and Vogel (1948) and on 19 descriptions of patients with established residual kernicterus, some of which cases were, however, of doubtful aetiology (Hoffmann and Hausmann, 1926; Burghard and Schleussing, 1933 ; de Lange, 1934, 1936 ; Zimmerman and Yannet, 1935 ; Biemond and van Creveld, 1937 ; Fitzgerald, Greenfield, and Kounine, 1939 ; van Bogaert, 1947 ; Mann and Courville, 1948 ; McLardy, 1948 ; Christensen and Vestergaard, 1949 ; Crome, 1955). These descriptions convey the impression that the main lesions in residual kernicterus are situated in the globus pallidus, the subthalamic nucleus and hippocampus, and that they are characterized by lack of myelination, degeneration with loss of nerve cells, and fibrous gliosis. Some of the workers have also mentioned changes elsewhere, including degeneration of cortical nerve cells, and these changes are, perhaps, more common than suggested in the published accounts.

It is reasonable, nevertheless, to infer that the brunt of the lasting damage in most cases of $R h$ sensitization is borne mainly by subcortical formations. The clinical features of the present case were dominated, contrariwise, by full idiocy, the morbid anatomical picture by gross cortical atrophy. The subcortical areas had escaped severe damage, and the absence of the characteristic lesions in the globus pallidus, subthalamic nuclei, and the hippocampus was yet a further mark of divergence from the usual findings.

Viewed as a lipoidosis, the present case falls into the group which includes amaurotic family idiocy and Niemann-Pick disease. The precise relationship between the two is still uncertain, and Peters (1951) refers to the many cases in which the two conditions were present in combination. 
In the opinion of Thannhauser (1950), they represent separate clinical entities in spite of similar retinal and neuronal changes. Sphingomyelin is known to be increased in cases of Niemann-Pick disease and ganglioside, containing neuronic acid, in amaurotic idiocy (Klenk, 1939). The biochemical difference may not be decisive, the two conditions being merely related variants of similar pathogenetic processes (Tropp and Eckhardt, 1936 ; Sperry, 1942). Clinically and morphologically, however, Niemann-Pick disease is characterized mainly by the splenohepatomegaly, and amaurotic family idiocy by the neurological changes.

The biochemical findings in the present case were, unfortunately, inconclusive. The cerebral white matter showed reduction in cholesterol and cerebroside, and increase in ester cholesterol. This is a non-specific change consistent with the histological picture of advanced demyelination. The spleen showed a small but definite increase of lipids. The total lipid carbohydrate was, however, 10 times higher than normally. This could have been due to an increase of either cerebrosides, gangliosides, or an unknown lipid-bound carbohydrate.

Most of the recorded cases of amaurotic family idiocy were infants or older children who presented a picture of progressive mental and physical deterioration, paralysis, and blindness accompanied by retinal changes. These cases have been classified, rather arbitrarily, into infantile, late infantile, juvenile, and adult forms. It is now known that congenital forms of amaurotic family idiocy may also occur (Norman and Wood, 1941) and a case of congenital Niemann-Pick disease has, likewise, been described by Burne (1953).

The recorded findings in this group of diseases have been sufficiently varied to justify the inclusion of the present case in it, although the severity of the neurological changes was possibly greater. The signs were so marked from the onset as to leave little room for manifestations of the progressive deterioration which was apparent from the histological evidence of continuing destruction in the brain. The retinal changes were more widespread than in most cases of amaurotic family idiocy. The structural changes in the cerebellum corresponded broadly with those described by Bielschowsky (1920-21) under the term of " centripetal" type of cerebellar degeneration, characterized by sclerosis, atrophy of the granular layer, the moss and climbing fibres and basket cells, and by the persistence of the Purkinje cells. This type of degeneration was considered by him to be characteristic of amaurotic idiocy in contrast to the "centrifugal" type which occurs in primary cerebellar degeneration. The slight degree of involvement of the spleen, liver, and lymph nodes in the present instance would indicate, in the absence of conclusive biochemical results, its intermediate position between amaurotic idiocy and Niemann-Pick disease if, indeed, the two are distinct. The incestuous relationship of the patient's parents is in conformity with the recessive mode of inheritance of amaurotic family idiocy.

\section{Summary}

Severe neurological disease marked by total idiocy and paralysis developed in an infant who suffered from erythroblastosis foetalis following $\mathrm{Rh}$ factor incompatibility. His parents were brother and sister. He survived to the age of 2 years and 7 months, and the pathological findings included widespread cerebral lipoidosis with a moderate number of abnormal lipoid-containing cells in the liver, spleen, and lymph nodes. Damage in the brain was chiefly cortical, the subcortical centres being relatively spared.

I wish to acknowledge the help given to me by my colleagues at the Fountain Hospital and access to case records. I am particularly indebted to Miss Craib for the social history of this case, and to $\mathrm{Mr}$. R. Rodnight and Dr. L. I. Woolf for the biochemical investigations.

\section{REFERENCES}

Becker, P. F. L., and Vogel, P. (1948). J. Neuropath., 7, 190. Bielschowsky, M. (1920-21). J. Psychol. Neurol. (Lpz.), 26, 123. Biemond, A., and Crevald, S. van (1937). Arch. Dis. Childh., 12, 173. Bogaert, L. van (1947). Ann. paediat. (Basel), 168, 57.

Burghard, E., and Schleussing, H. (1933). Klin. Wschr.. 12, 1526. Burne, J. C. (1953). J. Path. Bact., 66, 473.

Christensen, E., and Vestergaard, E. (1949). Acta psychiat. (Kbh.), 24, 363 .

Crome, L. (1955). J. Neurol. Neurosurg. Psychiat.. 18, 17.

_- Kirman, B. H., and Marrs, Margaret (1955'. Brain, 78, Pt. 4, p. 514 .

Evans, P. R., and Polani, P. E. (1950). Quart. J. Med. (n.s.), 19. 129. Fitzgerald, G. M., Greenfield, J. G., and Kounine, B. (1939). Brain, 62, 292 .

Hoffmann, W., and Hausmann, M. (1926). Mschr. Kinderheilk., 33, 193.

Klenk, E. (1939). Hoppe-Seyl. Z. physiol. chem., 262, 128.

Lange, C. de. (1934). Jb. Kinderheilk., 142, 255.

-(1936). Rev. fran.. Pidiat., 12, 793.

Mann. L. B., and Courville. C. B. (1948). Bull. Los Angeles neurol. Soc., 13, 69.

Soc., 13, 69.
McLardy, T. (1948). Brain, 71, 290.

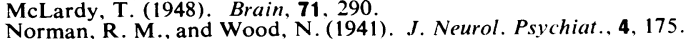

Pentschew, A. (1948). Arch. Psychiat. Nervenkrank., 118-180, 118. - (1949). Nervenarzt, 20, 220.

Peters, G. (1951). Spezielle Pathologie der Krankheiten des zentralen und peripheren Nervensystems, p. 391. Thieme, Stuttgart.

Pickles, M. M. (1949). Haemolytic Disease of the Newborn. Blackwell,

Oxford.

Sperry, W. M. (1942). J. Mt Sinai Hosp., 9. 799.
Thannhauser, S. J. (1950). Lipidoses, 2nd ed., p. 214. Oxford University Press, New York.

Tropp, C., and Eckardt, B. (1936). Hoppe-Seyl. Z. physiol. Chem., 243,38 .

Zimmerman, H. M., and Yannet, H. (1935). Amer. J. Dis. Child., 49, 418 . 